\title{
A Rare Case Report of Pseudo Pancreatic Cyst in a Child
}

\author{
Syed Athhar Saqqaf ${ }^{1}$, Amar Taksande², Revat Meshram³ \\ 1, 2, 3 Department of Paediatrics, Jawaharlal Nehru Medical College, Sawangi, Wardha, Maharashtra, India.
}

\section{INTRODUCTION}

It is difficult to diagnose pancreatic cysts in children. Any previous history of acute pancreatitis is very important because it can lead to a wide set of complications like pseudocyst, pancreatic necrosis, splenic venous thrombosis etc. The most known and common cause of pancreatic pseudocyst in children is trauma. The characteristic features of pancreatitis include abdominal pain, serum lipase or amylase values three times more than that of the normal range and characteristic radiological features.

Pancreatic pseudocyst may occur in $15 \%$ of children with acute pancreatitis as a complication. ${ }^{1}$ Pancreatic juice collection enclosed by a wall of granulation or fibrous tissue, is defined as a pseudocyst. As the resulting cyst has no true endothelial lining, it is classified as a pseudocyst. ${ }^{2}$ The pseudocyst contains inflammatory pancreatic fluid, mainly the lipase enzyme or semisolid matter.

The incidence of pseudocyst is relatively low $1.6 \%$ - $4.5 \%$, or 0.5 - 1 per 100000 adults per year. ${ }^{2}$ Very few cases of pancreatic pseudocyst have been reported in world literature. Commonly, it develops as a sequel of acute or chronic pancreatitis. It develops around 4 weeks after the episode of acute pancreatitis. ${ }^{3}$ It is characterized by pancreatic inflammation, abdominal pain and raised levels of serum digestive enzymes. ${ }^{4}$ Here we discuss a case report of pancreatic pseudocyst in a 10-year-old male child presenting with history of abdominal pain and decreased appetite.

\section{PRESENTATION OF CASE}

A 10-year-old male child, born out of a non-consanguineous marriage was brought to outpatient department with complaints of pain in abdomen and decreased appetite since one month and vomiting since three days. The abdominal pain was insidious in onset, episodic and dull aching type in the epigastric region with increased intensity and frequency since 3 days.

It was associated with 5 - 6 episodes of vomiting which was non-bilious, nonblood tinged, non-foul smelling, and non-projectile and containing food particles. There was no history of fever, trauma, loose stools, and weight loss, yellowish discoloration of skin and sclera and convulsions. He received medication cefixime, ondansetron, pantoprazole and mefenamic acid from the private practitioner. There was no significant family history. The child's weight was 23 kilograms and his height was $136 \mathrm{~cm}$.

\author{
Corresponding Author: \\ Dr. Amar Taksande, \\ Department of Paediatrics, \\ Jawaharlal Nehru Medical \\ College, Sawangi, Wardha, \\ Maharashtra, India. \\ E-mail: amar.taksande@gmail.com
}

DOI: $10.14260 / \mathrm{jemds} / 2021 / 520$

How to Cite This Article:

Saqqaf SA, Taksande A, Meshram R. A rare case report of pseudo pancreatic cyst in a child.J Evolution Med Dent Sci 2021;10(31): 2535-2537, DOI:

10.14260/jemds/2021/520

Submission 26-03-2021,

Peer Review 28-05-2021,

Acceptance 05-06-2021,

Published 02-08-2021.

Copyright @ 2021 Syed Athhar Saqqaf et al. This is an open access article distributed under Creative Commons Attribution License [Attribution 4.0 International (CC BY 4.0)] 
He was afebrile, with vital parameters of pulse rate of 96 beats / minute, blood pressure of 96 / $64 \mathrm{mmHg}$, a respiratory rate of 22 breaths / minute, and oxygen saturation $98 \%$ on room air. On general examination revealed pallor, no icterus, and cyanosis or clubbing. There was no cervical lymphadenopathy. His abdomen was soft without hepatosplenomegaly. Normal heart sounds were auscultated on cardiovascular examination and air entry was bilaterally equal on respiratory examination. No neurological deficit on nervous system examination. Laboratory investigations revealed haemoglobin $11 \mathrm{~g} / \mathrm{dl}$, WBC 11,200 / $\mathrm{mm}^{3}$, platelets 3.31 lakh $/ \mathrm{mm}^{3}$. His serum electrolytes, liver function and renal function tests were within normal limits. His serum amylase and serum lipase levels were 109 and $139 \mathrm{U} / \mathrm{L}$ respectively, which were within normal limits. Ultrasonography of the abdomen and pelvis revealed a large multiseptated cystic lesion in epigastrium, posterosuperior to stomach and abutting left lobe of liver suggestive of hydatid cyst or large infected cyst. To confirm the diagnosis contrast enhanced computed tomography (CECT) abdomen was done. It demonstrated the multiple calcifications in the head, uncinate process, proximal body and main pancreatic duct of proximal body and tail region. There was evidence of a well-defined peripherally enhancing smooth walled cystic lesion (pseudocyst) noted in the epigastric region, posterosuperior to stomach which was suggestive of acute or chronic pancreatitis with dilated main pancreatic duct and pseudocyst (Fig 1,2).

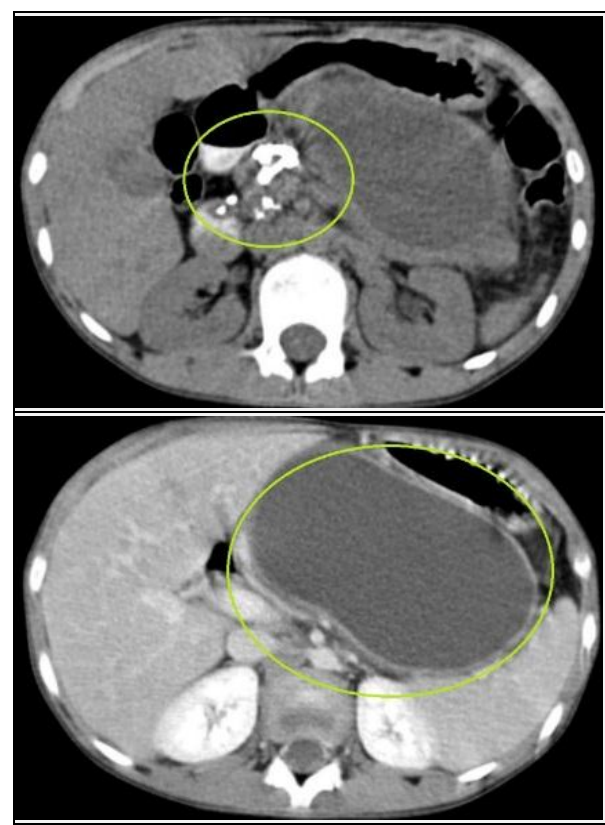

Figure 1. CT Scan Images Showing Multiple Calcifications in the Pancreatic Head

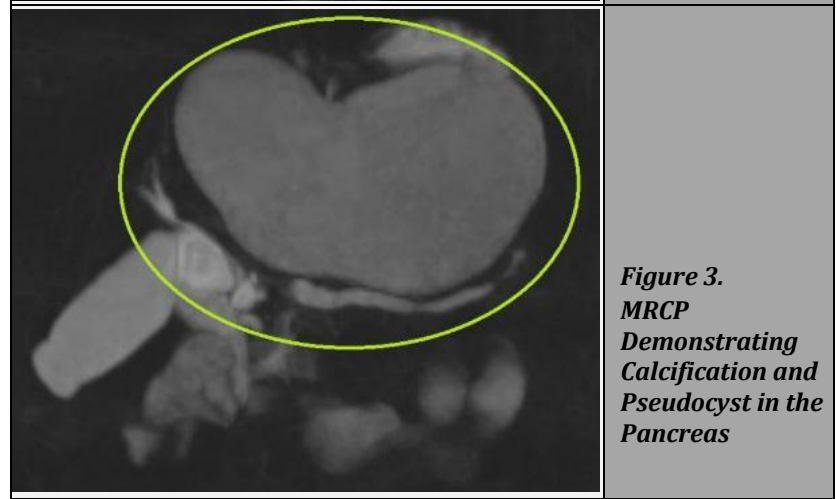

For the evaluation of pancreatic and biliary anomalies magnetic resonance cholangiopancreatography (MRCP) was done. It confirmed the changes of chronic pancreatitis with a large well-defined pseudocyst of pancreas noted anterior to the pancreas, appearing hypointense on $\mathrm{T} 1$ and hyperintense on T2 weighted images (Fig 3). He underwent a successful cystogastrostomy. The cystic fluid amylase levels were $9228 \mathrm{U}$ / L. Post operatively he recovered well with an uneventful further stay in hospital and was then discharged after 7 days.

\section{DISCUSSION}

In children, chronic pancreatitis usually presents as recurrent or chronic abdominal pain, impairing one's quality of life. Patient may also present with anorexia, nausea, vomiting and weight loss. In such cases, serum lipase and amylase levels are usually within normal limits or may be just mildly elevated. Pseudopancreatic cyst is uncommon in paediatric age group. ${ }^{5}$ In its rare occurrence, the pseudocyst is usually confined to the retroperitoneal space around the pancreas. ${ }^{6}$ In two studies, the frequency of pancreatitis was reported to be 3.6 and 13.2 cases per 100,000 children, respectively. 7,8

The pseudocysts appear to arise from disruptions of the pancreatic duct followed by extravasation of pancreatic secretions, mostly due to pancreatitis or trauma. ${ }^{9}$ A previous history of acute pancreatitis, if elicited, would be significant. 10 Trauma is the most common etiological cause. Other causes include biliary tract disease, raised intracranial tension, viral conditions and / or steroids. ${ }^{11}$ Patients may have a similar presentation as that of chronic pancreatitis, with / without the presence of an abdominal mass and jaundice. Differential diagnosis of this condition would include renal cysts, mesenteric cysts, re-duplication of gastrointestinal tracts, hydronephrotic cysts, dermoid cysts, teratomas, neuroblastoma, Wilms tumour, retroperitoneal hematomas and polycystic kidneys. ${ }^{12,13}$ The preferred modality for further evaluation of chronic pancreatitis and pseudocyst is either an USG or a CECT Abdomen. Sensitivity rates near $75 \%$ to $90 \%$ for ultrasonography in the detection of pancreatic pseudocysts. MRCP and endoscopic retrograde cholangiopancreatography (ERCP) are also essential for evaluating the biliary and pancreatic anomalies. Depending on the cause of chronic pancreatitis, endoscopic treatments include drainage of pseudocysts, stone extraction and pancreatic or biliary endoprosthetic stenting. Supportive care usually helps resolve most of the pseudocysts. Pseudocyst of pancreas although a rare condition in children is a clinically significant entity. Its management depends on the size of the pancreatic injury and availability of facilities for percutaneous, internal drainage and endoscopic procedures. In cases where percutaneous or endoscopic drainage of pseudocyst becomes difficult or complicated, cystogastrotomy is done. ${ }^{14,15}$

\section{CONCLUSIONS}

In conclusion, we report a rare case of pseudopancreatic cyst in a child. The timely detection of pseudopancreatic cyst and intervention can lead to satisfactory surgical outcomes. 
Therefore, it is essential to evaluate for pseudopancreatic cyst in any child presenting with a chronic abdominal pain.

Financial or other competing interests: None.

Disclosure forms provided by the authors are available with the full text of this article at jemds.com.

\section{REFERENCES}

[1] Pohl JF, Uc A. Paediatric pancreatitis. Curr Opin Gastroenterol 2015;31(5):380-6.

[2] Joda AE, Yaser A. Pancreatic pseudocyst in a 4-year old boy: case report. Mustansiriya Medical Journal 2016:15(3):16-22.

[3] Bhattacharya S. The pancreas. In: Williams NS, Bulstrode CJK. O'Connell PR, eds. Bailey and Love's short practice of surgery. 26 th edn. London: CRC Press 2013:1133-4.

[4] Morinville VD, Husain SZ, Bai $\mathrm{H}$, et al. Definitions of pediatric pancreatitis and survey of present clinical practices. J Pediatr Gastroenterol Nutr 2012;55(3):261-5.

[5] Janarthanan K, Balalakshmoji D, Sanathkumar HT, et al. Chronic pancreatitis presenting with pseudocyst of pancreas and pseudo-aneurysm of hepatic artery. Indian J Pediatr 2012;79(7):952-4.

[6] Benifla M, Weizman Z. Acute pancreatitis in childhood: analysis of literature data. J Clin Gastroenterol 2003;37(2):169-72.
[7] Keim V, Witt H, Bauer N, et al. The course of genetically determined chronic pancreatitis. JOP 2003;4(4):146-54.

[8] Rebours V, Boutron-Ruault MC, Schnee M, et al. The natural history of hereditary pancreatitis: a national series. Gut 2009;58(1):97-103.

[9] Habashi S, Draganov PV. Pancreatic pseudocyst. World J Gastroenterol 2009;15(1):38-47.

[10] Goyal S, Raju R, Yadav S. Pancreatic pseudocyst of gastrohepatic ligament: a case report and review of management. JOP 2012;13(4):439-42.

[11] Tomar S, Bakhshi S, Kabra SK, et al. Pancreatic pseudocyst complicating treatment of acute lymphoblastic leukemia. Indian Pediatr 2003;40(7):670-2.

[12] Rubinoff ML, Park C, Tauber J B, et al. Pancreatic pseudocysts in children report of a case and review of the literature. California Medicine 1967;07:13-514.

[13] Kilman JW, Kaiser GC, King RD, et al. Pancreatic pseudocysts in infancy and childhood. Surgery 1964;55:455-61.

[14] Werlin SL. Pseudocyst of the pancreas. In: Kliegman RM, Behrman RE, Jenson HB, et al, eds. Nelson Textbook of Pediatrics. 19 $9^{\text {th }}$ edn. Philadelphia: Elsevier Inc 2011.

[15] Giakoustidis A, Antoniadis N, Giorgakis I, et al. Pancreatic pseudocyst in a child due to blunt andominal trauma during a football Game. Hippokratia 2012;16(1):71-3. 